\title{
A avaliação institucional como instrumento de racionalização e o retorno à escola como organização formal
}

Licínio C. Lima'

I- Universidade do Minho, Braga, Portugal.

Contato: llima@ie.uminho.pt

\section{Resumo}

0 papel central da avaliação, da avaliação institucional e dos processos de garantia da qualidade de escolas e universidades nas políticas educacionais é objeto de discussão, também considerando a reforma do Estado. As teorias da nova gestão pública e as perspectivas gestionárias são consideradas como algumas das principais fontes de inspiração e de legitimação no contexto dominante de uma educação contábil. Dados empíricos preliminares resultantes do processo de avaliação externa de escolas básicas e secundárias portuguesas são apresentados e interpretados de acordo com os principais conceitos e representações organizacionais de escola presentes nos relatórios externos. Examinando algumas das imagens e dos significados de escola, cultura de escola, autonomia, objetivos, liderança e eficácia presentes nos relatórios de avaliação, o autor releva a importância das imagens formais, racionais e burocráticas de escolas. Várias questões de investigação são apresentadas tendo por base aquilo a que o autor chama o processo da hiperburocratização das organizações educativas. Algumas dimensões do conceito de burocracia de Max Weber são revisitadas, em articulação com perspectivas neocientíficas de garantia da qualidade e com as tecnologias da informação e comunicação. 0 autor sugere que maior relevância deve ser atribuída aos modelos formais e racionais de interpretação das organizações educativas, pois os processos de avaliação e de garantia da qualidade estão a contribuir para a formalização de escolas e universidades e para a intensificação do seu processo de racionalização, isto é, para a emergência de uma imagem analítica das escolas como hiperburocracias.

\section{Palavras-chave}

Avaliação institucional - Garantia da qualidade - Organização formal - Hiperburocracia. 


\title{
Institutional assessment as an instrument of rationalization back to the school as a formal organisation
}

\author{
Licínio C. Lima'
}

\begin{abstract}
The central role of evaluation, institutional assessment and quality assurance processes of schools and universities in education policy is object of discussion also considering the reform of the state. New Public Management theories and managerialist perspectives are considered some of the main sources of inspiration and legitimation in the dominant context of an audit education. Preliminary empirical data from external assessment of Portuguese primary and secondary schools are introduced and interpreted according to the main concepts and organizational representations of school found in external reports. Examining some of the central organizational images and meanings of school, school culture, autonomy, goals, leadership and effectiveness included in the external reviews, the author stresses the importance of formal, rational and bureaucratic images of schools. Several new research questions are presented for further inquiry based on the hypothesis of what it is called by the author the process of hyperbureaucratization of educational organizations. Some of the main dimensions of the concept of bureaucracy as presented by Max Weber are revisited in close relation with neo-scientific approaches of quality assurance and taking in consideration the use of information and communication technologies. Accordingly the author suggests that much more importance must be given to formal and rational models of interpreting educational organizations because assessment and quality assurance procedures are contributing to the formalization of schools and universities and to the intensification of their process of rationalization, $i$. e., to the emergence of an analytic image of schools as hyperbureaucracies.
\end{abstract}

\section{Keywords}

Institutional assessment - Quality assurance - Formal organization - Hyperbureaucracy.

I- Universidade do Minho, Braga,

Portugal.

Contact: llima@ie.uminho.pt 


\section{Introdução}

0 atual protagonismo da avaliação, no quadro das políticas educacionais, não remete apenas para as suas dimensões instrumentais e de controle, ao serviço de novas modalidades de regulação e metarregulação estatal das políticas públicas. A avaliação educacional, mais do que isso, é uma das máximas expressões, substantivas, das políticas educacionais contemporâneas, seja em escala nacional e local, seja em escala transnacional. Como Michael Young (1958, p. 33) observou, no seu célebre livro em que critica a ascensão da meritocracia, a competitividade internacional não ocorre apenas entre economias, mas também entre escolas.

Da procura das escolas eficazes à produção de rankings, dos testes comparativos internacionais à avaliação do desempenho e à promoção diferenciada dos docentes, da avaliação institucional aos orçamentos competitivos, a avaliação tornou-se o cerne da política educacional, típica do "Estado competidor" (BALL, 2007, p. 191), do "governo pela avaliação" ou pela "notação", que caracteriza as democracias da "idade da desconfiança” (ROSANVALLON, 2006, p. 78), própria do "Estado gestionário", segundo Clarke e Newman (1997), ou ainda do "Estado avaliador”, segundo Guy Neave (1988).

No que às organizações educativas concerne, uma parte dos argumentos recentes de legitimação da introdução, ou do reforço, de processos avaliativos - de alunos, de docentes e das próprias escolas e universidades - remete para: a ideia de crise da escola e de perda de qualidade, pretensamente derivadas da democratização do acesso (argumento de que o nível desce em função da democratização do acesso); o desenvolvimento profissional dos professores, numa base competitiva e de gestão de recursos humanos (no quadro do chamado neoprofissionalismo); o quesito da adequação do sistema escolar às necessidades da economia e à produção de habilidades economicamente valorizáveis, em busca de vantagens competitivas (no quadro do vocacionalismo dominante); o reforço das medidas de descentralização de poderes e de autonomia das escolas, que teria pretensamente ocorrido e que, agora, exigiria como contrapartida processos de controle a posteriori, de responsabilização, prestação de contas, accountability (AFONSO, 2012) (apoiando lógicas de devolução e de matarregulação).

Quanto ao reforço da autonomia das escolas, a orientação pode ser sintetizada pela máxima: para mais autonomia, mais avaliação. Mesmo quando, como no caso português, a situação é sui generis, uma vez que a avaliação externa das escolas dos ensinos básico e secundário foi introduzida para compensar uma autonomia, sobretudo retórica, por parte dessas escolas, as quais permanecem subordinadas a uma administração fortemente centralizada, a uma direção atópica, ou fora do seu lugar, localizada nos serviços concentrados e desconcentrados do Ministério da Educação, e não no interior de cada escola, assim originando uma autonomia técnico-instrumental, ou de execução (LIMA, 2008, p. 161-165); uma espécie de autonomia heterogovernada, oximoro (ou contradição nos termos) que venho usando. E mesmo na educação superior, onde as instituições portuguesas gozam, em termos jurídicos, de amplas margens de autonomia, os últimos anos vêm acentuando dinâmicas de uma autonomia sitiada. Uma autonomia procedimental e limitada por efeito dos cortes de financiamento por parte do Estado, da adaptação a processos supranacionais de integração e a dinâmicas transnacionais de captação de financiamentos alternativos, de acordo com as orientações de um cânone gerencialista (LIMA, 2012a) e de um complexo hibridismo institucional de feição inovadora e adaptativa ante o ambiente competitivo (LIMA, 2013) que, em ambos os casos, assentam na superioridade da racionalidade econômico-empresarial.

A atual generalização da avaliação externa coincide com um défice quanto à autonomia das escolas, numa situação que se 
aproxima de muita avaliação para pouca, ou nula, autonomia, o que só por si é um indicador da dimensão política da avaliação, e até mesmo ideológica, ao desligar-se da realidade e produzir sobre ela uma espécie de máscara, ou de névoa, que dificulta a sua apreensão crítica.

Dentre os múltiplos impactos das políticas e práticas de avaliação externa, designadamente da chamada avaliação institucional, destaca-se uma intensifıcação da formalização dos objetivos, dos processos e das formas de organização e gestão das organizações educativas, bem como a alta racionalização, técnico-instrumental, da educação escolar. No contexto mais geral da chamada garantia da qualidade, consideravelmente influenciada pela nova gestão pública e pelo elogio dos modos de gestão privada e empresarial, escolas e universidades vêm sendo crescentemente subordinadas a metas quantificáveis com precisão, a comparações de performance, a exercícios contabilísticos e de mensuração pretensamente capazes de induzir a competitividade e, por essa via, a melhoria da qualidade. 0 conceito de qualidade que é adotado surge conotado com a escassez de recursos e com atributos distribuídos de forma rara e assimétrica no interior de uma dada população, dessa feita justificando, com frequência, a imposição de quotas e uma acentuada diferenciação de estatutos e de classificações e, por essa via, legitimando orçamentos competitivos capazes de premiar a excelência.

\section{A avaliação no contexto da educação contábil}

Em geral, as atividades de avaliação são bem conhecidas nas organizações educativas e são tarefas de há muito desempenhadas por educadoras e professores. Agora, porém, a avaliação foi transformada num instrumento de governação política e numa técnica de gestão. De resto, a educação passou a importar, da economia e da gestão, novas teorias e metodologias avaliativas, com destaque para a gestão da qualidade total e para os processos de garantia da qualidade. No limite, a política pelos resultados avaliados arrisca-se a despolitizar a ação política, naturalizando o processo de decisão, como se este representasse um processo predominantemente técnico-instrumental, típico de uma pós-democracia gestionária, em busca da decisão ótima, através do cálculo racional, segundo a teoria padrão da decisão.

É como se tudo fosse a exame, ao melhor estilo escolar tradicional, mas de forma desvinculada dos sistemas de regras, da cultura educacional e da ação pedagógica, sendo a avaliação transformada num complexo sistema de expertise, de regras periciais que transcenderiam a legitimidade, os saberes teóricos e práticos dos atores escolares, justificando, assim, a emergência dos novos profıssionais da avaliação e da garantia da qualidade. De tal forma que, para professores e alunos, as novas modalidades de avaliação e de garantia da qualidade tendem a evidenciar uma natureza estranha, hierárquica, externa e heterônoma, atribuindo-lhes o papel de objetos, mais do que o de sujeitos, da avaliação. Frequentemente, eles são executantes, produtores de dados e evidências, subordinados a rigorosos protocolos e tecnologias avaliativas.

Especialmente quando a comparabilidade e a competitividade são consideradas centrais, no contexto de sistemas de avaliação que visam a hierarquizar performances diferenciadas e competitivas, com consequências financeiras, de status ou mesmo quanto à continuidade de projetos, cursos ou instituições, uma certa "geometrização do saber" ocorre, segundo métricas, padrões, categorias de alcance mais ou menos universal (KELLER, 2008). Essa concepção instrumental e utilitarista de avaliação não visa à produção de conhecimento social, mas é sobretudo orientada para a produtividade e o controle em contextos de reforma do papel do Estado, e tem resultado numa avaliação e em processos de garantia da qualidade fortemente administrados, de feição positivista e neocientífica, em que os riscos de alta racionalização e formalização burocráticas, orientadas para o controle, têm sido 
observados (DIAS SOBRINHO, 2008, p. 83). Já o sociólogo alemão Max Weber (1964, p. 750), no início do século XX, havia observado: "Só a moderna burocratização leva às suas últimas consequências os exames racionais especializados".

A avaliação externa de alunos, de escolas e universidades tende a ser desvinculada da investigação social, tal como da prática pedagógica de cada professor, para ser usada como instrumento de auditoria, à luz de uma concepção gestionária, orientada para a informação dos decisores políticos e para a alocação diferenciada de recursos considerados escassos.

Os processos dominantes nessa avaliação evidenciam uma espécie de quantofrenia, de acordo com o conceito usado pelo sociólogo Pitirim Sorokin, em meados do século XX, então a propósito daquilo que imperava nas ciências psicossociais e que podemos estender à educação e à pedagogia oficial. Sorokin (1965, p. 51) chamou a atenção para a testomania que, segundo ele, conduz a que "quase todos os indivíduos sejam testados, desde o berço até à cova, antes e depois de acontecimentos importantes na sua vida", através da ação dos respectivos testocratas. Os exames dominam, mesmo quando, recorda o autor, Tolstoi obteve fracas notas em redação, Hegel não satisfez em filosofia, e no Conservatório de Milão ninguém dava nada por Verdi.

Entretanto, segundo Sorokin, a matemática, embora sem culpa própria, foi sendo instrumentalizada ao serviço daquilo a que chamou o culto da numerologia. Uma espécie de nova doença terá emergido então: a quantofrenia. Em tais circunstâncias, observa o autor (SOROKIN, 1965, p. 103), "o uso de métodos matemáticos transforma-se numa preocupação meramente quantofrénica, nada tendo em comum com a matemática". Tal como, concluo eu, os educadores não são educometristas, mas antes pedagogos lato sensu, que sabem avaliar pedagogicamente. Sabem, também, reconhecer a importância do incomensurável em educação e, ainda, que o objetivismo é frequentemente enganador e alienante, podendo resultar numa cilada, como lhe chamou Hadji (1994).

Porém, a avaliação quantofrênica assenta na crença de que tudo é passível de mensuração e de que tudo aquilo que se mede é verdadeiro e se pode comparar e alcançar mais facilmente; os dados correspondem à realidade objetiva, sem mediações teóricas, políticas e outras capazes de produzir, ou de fabricar, a realidade, não sendo, portanto, construções sociais engendradas pelos próprios referenciais e critérios de avaliação. A partir do cálculo objetivo e da medição dos resultados, desvalorizam-se os processos e os resultados mais difíceis de captar e de contabilizar, favorecendo-se a estandardização, a exterioridade, a quantificação e a distância, pretensamente incontaminada, entre avaliadores e avaliados.

0 caráter olímpico, tal como uma certa arrogância objetivista, que marcam essa avaliação, provêm de uma epistemologia positivista e da adesão a pedagogias científicas e racionalizadoras, bem conhecidas no passado, e que têm sido recuperadas no presente. Não admitir que as modalidades, as regras e os processos de avaliação não se limitam a observar a realidade, mas que também intervêm sobre ela, projetam valores e orientações de todo o tipo, afetam as práticas dos atores, optam a favor e contra certas perspectivas científicas, pedagógicas, organizacionais, é criticável. Com efeito, uma avaliação educacional à margem de uma concepção política e organizacional de escola, ou para além de concepções educacionais, de opções curriculares e didáticas, representa uma impossibilidade, mesmo que os profissionais da nova divisão do trabalho avaliativo insistam em afirmar que nada sabem de educação e de pedagogia. 0 que frequentemente é verdade, pois a pedagogia foi esmagada pelas tecnoestruturas organizacionais da avaliação, pelos seus departamentos, agências, organizações internacionais e, mesmo, empresas da qualidade.

Porém, uma avaliação racionalista e tecnocrática é compatível com aquilo que designo por educação contábil (LIMA, 1997), ou 
seja, aquela educação que conta, coincidindo com a educação que mais facilmente se deixa contar, mensurar, comparar e hierarquizar, através de vários agentes contadores e de complexos processos de contadoria.

A educação contábil define a educação que conta em função do carácter contável, mensurável e comparável dos resultados produzidos, tendendo a conceptualizar o aluno como uma matéria-prima moldável através de processos de produção escolar. Ora, pelo contrário, como lembrou Paulo Freire, “o aluno não é um corpo indeciso e acomodado, a que o formador dá forma" (FREIRE, 1996, p. 25). Como sabemos, tem vontade própria e, embora alguns o esqueçam, só aprende quando quer. Donde o ensino fica refém, para ser ensino verdadeiro, da aprendizagem de cada um dos alunos.

Ao invés, tem-se instituído um paradigma positivista de avaliação, baseado no "mito da medição" (BROADFOOT, 1996), ou no "mito da mensuração de valores", como lhe chamou Ivan Illich (1977, p. 78), como se a avaliação educacional pudesse constituir um procedimento puramente científico e técnico. Illich (1977, p. 77), através da sua crítica radical à escola produtivista, sentenciou: "Os valores institucionalizados que a escola inculca são valores quantificados. A escola inicia os jovens num mundo onde tudo pode ser medido, inclusive a imaginação e o próprio homem". Baseia-se, como tal, em concepções mecanicistas e instrumentais de organização (organon), que acentuam as relações de tipo mecânico, linear e causal, a ordem e a centralização, a forte conexão, enfatizando os elementos oficiais, formais e estruturais, definindo os objetivos e as tecnologias organizacionais e de avaliação como certos, estáveis e consensuais e as escolas como organizações em busca da realização de objetivos, através da utilização de processos racionais de decisão. É essa imagem hiperracionalista, em oposição às imagens políticas, culturais, subjetivas e de ambiguidade, entre outras, que convoca à medição da performance, à comparação, à competitividade e à emulação. Ignora-se, assim, que "A medição é inevitavelmente um dispositivo tanto político quanto técnico, que confere poder àqueles que o controlam" (BROADFO0T, 1996, p. 206). E daí, também, a ideia fortemente trabalhada em termos de legitimação política perante a opinião pública de que mais avaliação, traduzida por mais exames, por maior rigor e por mais seleção, corresponde a mais e melhor educação; resultado mais plausivelmente atingível, pelo contrário, através da prática de processos de avaliação formativa (contextualizados, não imediatamente generalizáveis nem universalmente comparáveis e hierarquizáveis) do que através da avaliação sumativa externa, de tipo contábil.

\section{Avaliação institucional, racionalização e formalização}

As dimensões de tipo racionalista e formalista transparecem com elevada frequência na legislação e noutros documentos, por exemplo, nos relatórios de avaliação externa das escolas: o pressuposto da definição de metas claras, avaliáveis e mensuráveis; a defınição de prioridades e de planos de ação para resolver problemas; a busca de uma visão da escola, expressa com clareza e produzida pelas lideranças; o planejamento estratégico a longo prazo. Outros elementos incluem, ainda, a capacidade de a escola atrair alunos, de captar verbas próprias, o grau de adequação das instalações, espaços e equipamentos, parecendo ignorar-se que, em muitos casos, tais elementos se encontram mais dependentes do poder central, ou municipal, do que da decisão nas escolas. Ao tomar a escola como unidade de gestão, manifesta-se uma visão insular, atomizada, como se os avaliadores estivessem perante instituições dotadas de autonomia. Como se, pelo fato de passar a existir avaliação externa das escolas, passasse a sair confirmada, empiricamente, a autonomia das escolas.

Mas é na análise dos relatórios de avaliação externa das escolas que se poderão encontrar as dimensões organizacionais mais 
interessantes e significativas, a exigir ulteriores aprofundamentos. Refiro-me, por exemplo, a indícios de uma concepção de cultura organizacional de escolas de feição integradora e consensualista, como se se tratasse de uma coisa ou de um artefato, construído pela direção unipessoal de cada escola, a partir do qual o envolvimento de alunos, professores, pais e mães, comunidade local fosse sinônimo de participação e a esta fossem associados o consenso, a harmonia e a auscultação do outro, mais do que a participação em processos de tomada da decisão, o dissenso e o conflito de agendas e interesses. Outro aspeto relevante é o que se prende com um referencial fortemente articulado, de natureza racional-burocrática, para interpretar as relações entre o projeto educativo da escola e o seu plano de atividades, projeto curricular, regulamento interno etc., esquecendo as conclusões da investigação, que têm chamado a atenção para a "débil articulação" (WEICK, 1976) entre tais elementos, não apenas no interior das escolas, mas também fora delas.

Do ponto de vista dos avaliadores externos, existem vários elementos naturalizados e imediatamente associados a dimensões positivas (ver TORRES; PALHARES, 2009), sem outra justificação ou ponderação: a angariação de verbas, a assinatura de protocolos e a celebração de parcerias, a inovação, a preocupação com a imagem da escola e com a construção de uma cultura escolar positiva, parecendo ignorar-se as possíveis derivas dessas dimensões, designadamente através de processos de fabricação da imagem das escolas (BALL, 2002), de promoção e marketing, ou mesmo de um certo ilusionismo para influenciar os avaliadores.

A amostra de relatórios que analisei revela textos especialmente críticos quanto à falta de hierarquização e calendarização dos objetivos e quanto a resultados escolares abaixo da média nacional, sem tomar em consideração o contexto e o ponto de partida de cada escola. Pelo contrário, os avaliadores apreciam positivamente a capacidade de autorregulação das escolas, mesmo sem esclarecerem o que se deve entender por isso, principalmente num contexto de generalizada heteronomia. Em ambos os casos, parece que, subitamente, o poder central desaparece e a escola emerge, solitária, à margem das relações de poder com a tutela política e a administração central, fora de conflitos e tensões, e de toda a gama de processos de microgestão. A escola tende a ser representada como um instrumento técnicoracional e não como uma organização cultural e com vínculos sociocomunitários. Há, nos relatórios de avaliação externa, pouco lugar para a discussão de questões educacionais, de modelos pedagógicos, de práticas diferenciadas de organização e gestão, de relações entre o relatório de avaliação interna e o relatório de avaliação externa, e, curiosamente, os processos de tomada de decisões nessas escolas são ignorados.

Ainda com pouco significado, os elementos indiciários já antes apresentados noutro lugar (LIMA, 2012b) não podem ser tomados como conclusões, mas como possíveis hipóteses de trabalho para estudos futuros. De entre as questões suscitadas, destaco as seguintes: a) quando se fala de autoavaliação das escolas, tais escolas gozam já de autonomia avaliativa, relevando das prerrogativas de autogoverno e da capacidade de negociação de referenciais de avaliação com os avaliadores externos? b) o exercício de avaliação institucional não se encontra demasiado dependente, ou mesmo sobredeterminado, em função de regras heterônomas? c) a avaliação institucional é mais avaliação ou é mais recolha e gestão da informação de acordo com os quesitos da avaliação externa, ou dos "instrumentos de apoio à auto-avaliação"? d) a avaliação institucional é mais da ordem da prestação democrática de contas, em contexto de autonomia, ou é mais da ordem da extração de contas através de uma instância inspetiva e de processos relativamente estandardizados? e) o que a avaliação externa avalia verdadeiramente no contexto de uma administração centralizada? 
Avalia escolas autônomas ou, sobretudo, a execução local, sobredeterminada pela administração central, das decisões tomadas pelo centro sobre as suas periferias? f) uma boa parte dos resultados da avaliação externa das escolas não seria imputável aos governos e à administração central, revelando-se assim uma espécie de auto-avaliação do centro político-administrativo sobre si mesmo, embora realizada de forma fragmentada, e indireta, através das suas extensões locais?

0 debate teórico e a pesquisa empírica, ambos com evidentes implicações práticas, ficam em aberto, especialmente por referência a distintas concepções organizacionais de escola. No contexto da avaliação institucional, o que significa a escola como organização educativa? Qual a natureza dos objetivos da escola, das suas tecnologias e dos seus processos de participação e de tomada de decisões? Qual a concepção de aluno? A de simples cliente, ou consumidor, a de matéria-prima em processo de transformação, ou a de sujeito em processo de aprendizagem e membro da organização?

0 que é uma boa liderança escolar e uma cultura de escola positiva? Apenas novos instrumentos de regulação e de produção de resultados escolares, induzidos pelos discursos gestionários, ou categorias de análise teoricamente sustentadas e com potencialidades interpretativas, segundo distintas abordagens teóricas cujo estudo é indispensável à compreensão das políticas e das práticas de avaliação escolar?

Esta avaliação educacional, de tipo hiperburocrático, resulta não apenas da não superação dos mais importantes traços da racionalidade técnico-instrumental que caracterizam a constelação de dimensões a que Weber chamou burocracia, mas também da burocratização extensiva e em profundidade do processo educativo, da obsessão pela escolha ótima, da imposição da performance competitiva baseada em resultados quantificáveis, de novas formas de controle e de escrutínio da ação dos profıssionais. A avaliação hiperburocrática é ainda reforçada: pela sua natureza crescentemente global, ou transnacional, em termos de integração e comparação; pela velocidade e fiabilidade do tratamento de grandes massas de dados, através do recurso às tecnologias da informação e comunicação; por uma espécie de taylorismo informático que impõe novas formas de controle automático nas escolas, a estandardização de categorias e a uniformização de processos e de tempos, apoiando uma recentralização da administração do sistema escolar que é favorecida pela automação, tal como Maurício Tragtenberg (2006, p. 266) admitira; por uma maior especialização e divisão do trabalho pedagógico e avaliativo; por uma deslocalização das démarches avaliativas para instâncias superiores ou agências externas; pelo apelo a uma base científicoracional, capaz de dar resposta à complexidade dos problemas e de legitimar tecnicamente os resultados produzidos e as consequências da avaliação; pela introdução de departamentos de garantia da qualidade e de monitorização sistemática, através da ação de novas categorias de profıssionais especializados em avaliação, como acontece nas universidades; pelas articulações crescentes entre avaliação de resultados e gestão por resultados, instituindo contratos de performance e orçamentos competitivos.

Essa visão utilitarista da avaliação, orientada para a produtividade e o controle, para a instrumentalização da educação, tem resultado numa avaliação educacional fortemente administrada, de tipo neocientífico. As concepções organizacionais de escola inerentes à referida visão hiperburocrática acentuam as dimensões formais e objetivas, o cálculo racional e o planejamento, a forte articulação, de tipo mecânico, entre os diferentes componentes da organização escolar, a centralização, a ordem e a hierarquia. Trata-se de uma imagem organizacional hiper-racionalista, que concebe as escolas como instrumentos racionais em busca da realização de objetivos não problemáticos, através de tecnologias fiáveis, enfatizando as suas dimensões formais e estruturais e a forte 
conexão, linearidade e causalidade do mundo organizacional (LIMA, 2006).

As teorias organizacionais formalistas e racionalistas adquirem, por isso, centralidade, desvalorizando a racionalidade limitada outrora apontada por Herbert Simon (1970), a incerteza e a ambiguidade dos objetivos e das tecnologias educacionais, a diversidade cultural e os conflitos políticos, as distintas e concorrentes lógicas de ação em contextos micropolíticos (BACHARACH; MUNDELL, 1993).

\section{Avaliação, hiperburocracia e o retorno à escola como organização formal}

As orientações dominantes em torno da excelência, da garantia e da gestão da qualidade, da avaliação e prestação de contas, têm desempenhado um papel central no processo de racionalização de escolas e universidades. Consequentemente, em termos de pesquisa, ganha protagonismo a abordagem teórica da escola como organização formal, ou seja, sobressaem as perspectivas de análise de tipo racional-burocrático e de sistema social. As imagens organizacionais de pendor mecanicista e técnico-instrumental tornaram-se mais comuns, desde logo a partir dos discursos políticos que, paradoxalmente, insistem nas críticas à racionalidade burocrática, prometendo a desburocratização das escolas e universidades e práticas de feição pós-burocrática. Prometem, ainda, mais descentralização e autonomia para as organizações educativas, mais participação, organizações inovadoras e empreendedoras, em busca da excelência.

0 governo pela avaliação e as organizações orientados pelos princípios da performance competitiva, da flexibilidade e da mudança teriam sido capazes de superar a administração burocrática, nas diversas dimensões que foram criticamente estudadas por Max Weber. Um dos instrumentos privilegiados de desburocratização, no contexto da nova gestão pública, seria o reforço da avaliação e dos processos de garantia da qualidade, contribuindo para a constituição de organizações educativas mais abertas aos clientes e a outros interessados, mais dependentes de orçamentos competitivos e da competição por alunos, o que as forçaria à introdução de lógicas de concorrência com outras organizações e à adoção de mercados internos no seu interior (entre faculdades, departamentos, cursos, classes etc.). A burocracia estaria morta, ou a caminho de ser, finalmente, extinta, de acordo com as promessas das reformas organizacionais e das novas teorias da qualidade. Mas essas promessas de desburocratização ocorrem, em simultâneo, com a burocratização das escolas, isto é, com a sua racionalização e formalização. Implicando sempre uma questão de grau, em termos weberianos, a burocracia educacional tem sido objeto de uma intensificação sem precedentes, acompanhada por objetivos de modernização e de racionalização de tipo econômico e técnicoinstrumental, servidos por poderosas tecnologias da informação e comunicação.

À primeira vista, os discursos políticos e as reformas organizacionais parecem incompatíveis com os argumentos que aqui apresento. E também a maioria dos estudos tem subalternizado a teoria da burocracia, deixando-se atrair pelas abordagens pósburocráticas da autonomia, flexibilidade e adhocracia, pelas promessas de participação, de decisão democrática e de cidadania organizacional, pelos conceitos de organização em rede e de ação pública, entre outros, e confundindo desmaterialização dos processos administrativos com desburocratização.

Entretanto, no domínio da análise sociológica das organizações educativas, a reação, justificada e academicamente produtiva, contra o quase monopólio das interpretações burocráticas e racionalistas que dominaram até à década de 1970 contribuiu para um pluralismo teórico sem precedentes, de que muito nos temos beneficiado. Há mais de duas décadas que defendo as vantagens das análises plurais e multifocalizadas das organizações 
educativas, o cruzamento hermeneuticamente produtivo entre distintos modelos, faces, imagens das organizações educativas, contra o exclusivo das interpretações jurídicas, das prescrições doutrinárias das correntes da gestão, do monolitismo das interpretações burocrático-racionais e formais, e das visões funcionalistas e sistêmicas. Embora criticando o ecletismo e as tendências para a fragmentação dos estudos organizacionais da educação, sou favorável ao exercício sustentado dos olhares cruzados, e até mesmo tensos e contraditórios, o qual contribuiria para ultrapassar as lógicas impostas pelos paradigmas sociológicos de análise organizacional (BURRELL; MORGAN, 1979) enquanto linhas paralelas que nunca se encontram nem dialogam, dessa forma incorrendo numa incomensurabilidade paradigmática. Tenho criticado a excessiva centralidade dos modelos formais e racionais, defendendo que sejam desafiados por outras abordagens não mutuamente exclusivas como são as análises políticas, culturais, de ambiguidade, neoinstitucionais, entre outras. Essas e outras perspectivas sociológicas de análise são modos de ver, de interpretar, de estudar; são lentes que, se não relevam imediatamente das realidades educativas, são referenciais teóricos que nos ajudam a compreendê-las.

Em qualquer caso, a pertinência teórica das diferentes abordagens não é absolutamente independente da realidade organizacional a estudar. No limite, a forma como compreendemos as organizações educativas e lhes atribuímos sentidos não espelha, nem reflete de forma límpida, tais organizações, mas, por outro lado, não deixará de interferir nessas organizações enquanto contextos sociais relativamente condicionados pelas nossas representações.

Se as interpretações racionais, formais ou burocráticas das organizações educativas nunca chegaram a ser completamente afastadas, foram realmente esbatidas a partir da década de 1970. A "ambiguidade" e a "anarquia organizada” (COHEN; MARCH; OLSEN, 1972;
COHEN; MARCH, 1974) e o conceito de "sistema debilmente articulado" (WEICK, 1976), tal como a influência exercida pelo trabalho de Victor Baldridge (1971) no domínio da análise política das universidades, concorreram teoricamente com as visões racionalistas de organização formal, mais ou menos descrita, de forma singular, nos estatutos e nas regras formais, representada graficamente através de organogramas eloquentes, mas planos, sem profundidade nem dinamismo, enclausurados por injunções jurídicas e administrativas. Dessa forma, permaneceram relativamente indiferentes às ações dos atores, subordinados teoricamente a uma certa monorracionalidade e a objetivos organizacionais representados como consensuais e sem disputa, alcançados através de tecnologias certas e estáveis, por processos racionais e lineares de decisão, em busca da solução ótima, visando à máxima eficiência e eficácia. Mas até mesmo quando, em 1965, no Handbook of organizations, editado por James March, Charles Bidwell escreve um capítulo sobre a escola como organização formal, o autor revela, de certo modo contraditoriamente, como as escolas parecem escapar a uma interpretação racionalformal, apresentando uma "fraca estruturação" e especificidades que só outras "lentes" teóricas viriam a permitir explorar, como por exemplo uma certa "invulnerabilidade" dos docentes relativamente a certas regras formais e alguma resistência à autoridade oficial (BIDWELL, 1965, p. 1014). As escolas e universidades, como organizações formais e complexas - no sentido que lhes atribuiu Amitai Etzioni (1974) -, em suma, como organizações burocráticas, nunca deixaram de estar presentes na pesquisa, designadamente a partir da influência de estudos sobre a sociologia da burocracia, como os de Martin Albrow (1970), Nicos Mouzelis (1975), Bengt Abrahamsson (1977), Stewart Clegg (1990), entre outros. Abrahamsson (1977), insistiu, vigorosa e pertinentemente, no fato de ser precipitado afastar a análise burocráticaracional das organizações, independentemente 
dos ataques de que era alvo e, especialmente, das propostas de desburocratização, ou de gestão democrática, que eram, alternativamente, apresentados no plano político, administrativo ou educacional. Vários autores chamaram a atenção para as contradições entre discursos políticos e projetos político-pedagógicos, por um lado, e, por outro, para a nossa incapacidade de transformar a dominação racional-legal na administração educacional. Tais contradições foram assumidas quando alguns autores, apesar de defenderem a democratização das organizações educativas e do seu governo, não deixaram de analisar a introdução de políticas de inspiração neotayloriana e de destacar o possível reforço da organização burocrática no contexto da introdução da racionalidade econômica e gestionária na educação, por influência da Nova Gestão Pública, das reformas do Estado e de suas parcerias com o mercado e a sociedade civil, pelo protagonismo da avaliação e da gestão da qualidade em grande escala e em termos comparativos e competitivos, pelo regresso, em força, dos exames nacionais estandardizados, pelo recurso generalizado à avaliação institucional.

Sob o lema da desburocratização da administração pública, pretensamente reinventada, tivemos dificuldades em interpretar o novo gerencialismo e os discursos a favor da descentralização, da devolução e da autonomia, da participação e da prestação de contas, das melhores práticas, dos benchmarks, da criação de mercados internos nas organizações. Foi, por vezes, difícil compreender como os ataques políticos à burocracia não provinham já das teorias democráticas e participativas, nem dos chamados adeptos da antiorganização, mas, pelo contrário, provinham dos defensores da reforma do Estado que apresentavam como critério a racionalidade econômica, o empreendedorismo, o protagonismo do cliente, num contexto em que a burocracia-racional e suas dimensões fizeram, e continuam a fazer, carreira.

Nesse contexto, a tão celebrada cultura de avaliação, entendida como quesito para escolas e universidades de melhor qualidade, mais competitivas e legitimadas socialmente, exigia uma interpretação à luz de uma cultura integradora, compatível com a análise formalburocrática das organizações, tendencialmente monorracionais, em função da hegemonia da otimização e da maximização. A cultura de avaliação é, afınal, a aceitação de processos e de lógicas de ação monocultural e monorracional, da racionalidade técnico-instrumental, do meio ótimo, produzida através da prática sistemática de um certo tipo de avaliação: uma avaliação racionalista, formalista, instrumental.

Não surpreende, por todas as transformações operadas ao longo das últimas décadas, que um dos pioneiros da teoria da anarquia organizada, Johan Olsen, tenha escrito um artigo intitulado "Talvez seja tempo de redescobrir a burocracia”. Aqui revela que a burocracia não é um dinossauro extinto pela Nova Gestão Pública ou pelas organizações em rede, de tipo cooperativo. Como Olsen (2005) observa, uma administração legal-burocrática comporta elementos institucionais e não apenas técnico-instrumentais, rotinas, certamente, mas não necessariamente maior rigidez. Weber, pelo contrário, considerou a burocracia maleável e adaptável às organizações públicas e privadas, ao Estado capitalista e ao Estado socialista.

Hierarquia, mercado competitivo e cooperação surgem hoje em complexas combinações em Estados, administrações e organizações marcadas por forte hibridismo. Cristopher Pollitt e Geert Bouckaert (2011, p. 118-125) falam da possível contraposição de um "Estado neoweberiano" ao modelo anglosaxão do "Estado-gestionário", moldado pela nova gestão pública. Os elementos weberianos, segundo os autores, compreendem a centralidade do Estado, o papel da democracia representativa e do direito administrativo, a preservação da ideia de serviço público. Já os elementos associados ao prefixo neo incluem a orientação para o cidadão através de alguns mecanismos de mercado, certas práticas de democracia direta complementares à democracia representativa, a 
combinação de processos de controle ex-ante e ex-post, a profissionalização do funcionário, acrescentando à sua condição de perito a de gestor profissional ao serviço das pessoas.

\section{Nota final}

São vários os elementos políticoadministrativos que poderiam ser convocados para justificar a intensificação da formalização e a alta racionalização em curso nas escolas e universidades. A avaliação institucional e os processos de garantia da qualidade parecem-me centrais a esse processo, a que tenho chamado de hiperburocratização da administração educacional (LIMA, 2012c), servido pelas tecnologias da informação e comunicação e respectivas plataformas informáticas.

A educação escolar, sem recurso à avaliação pedagógica e organizacional, parece uma impossibilidade, sobretudo porque alienaria as possibilidades de uma avaliação formativa e de uma avaliação institucional visando à melhoria das escolas e de seus processos educacionais. Mas só numa "escola examinatória", como lhe chamou Michel Foucault (1998, p. 156-148), só numa escola subordinada à vigilância, à rivalidade e ao "homem calculável", uma avaliação quantofrênica conhecerá plena justificação. A desumanização da educação e a alienação de docentes e discentes serão, nesse caso, um dos custos a suportar.

As teorias da avaliação, tal como muitas práticas avaliativas democráticas, comportam uma multiplicidade de alternativas capazes de desafiar o senso comum dominante. Caso contrário, temo que a educação seja transformada em cada vez mais avaliação e mensuração, e em cada vez menos educação e promoção de uma cultura integral do indivíduo; esta última crescentemente desvalorizada pelo rigorismo dos saberes considerados essenciais, embora quase sempre estreitos, e pela redução do conhecimento escolar à sua natureza contábil.
Quanto à formalização e racionalização (ou seja, à burocratização de alta intensidade) das escolas e à correspondente necessidade de recorrermos mais às perspectivas analíticas de tipo racionalista, creio ter deixado exemplos suficientes para discussão. As escolas e universidades são, cada vez mais, objetos de formalização e, por isso, cada vez mais e melhor interpretadas enquanto organizações formais. Isso foi também concluído, recentemente, por Francisco Ramirez (2013), a propósito dos impactos dos mecanismos de avaliação e garantia da qualidade nas universidades. Ramirez apresenta vários exemplos, desde os critérios para contratação e promoção de professores, passando pela avaliação para a concessão de tenure e pelos processos de garantia da qualidade, até aos relatórios anuais dos professores na Escola de Educação da Universidade de Stanford, cujo modelo apresenta no seu artigo.

As imagens das escolas e universidades como comunidades, colégios, arenas políticas, anarquias organizadas, sistemas debilmente articulados, entre outras, não se tornaram inúteis ou dispensáveis, mas as avaliações estandardizadas, de tudo e de todos, vêm transformando, quase totalitariamente, as organizações educativas em organizações altamente racionalizadas e formalizadas, com suas missões e visões, planos estratégicos, sistemas de auditoria e garantia da qualidade, em busca do estatuto de ator racional, à semelhança de um indivíduo que age estrategicamente, a fim de maximizar as suas oportunidades e de perseguir diligentemente os seus interesses. 0 empreendedor individual, inovador e criativo, que marcou o espírito do capitalismo, é mimeticamente reproduzido à escala das grandes organizações educativas do nosso tempo, que, de resto, há muito deixaram de ser realidades extraeconômicas. Nesses termos, difícil seria compreender a pretensa superação de uma boa parte das mais relevantes dimensões do tipo-ideal a que Max Weber (1964) chamou burocracia, ou "autoridade racional- 
legal”, cuja expansão irreversível vaticinou, alcance e a velocidade que agora são inerentes embora muito longe de poder imaginar o à ciberadministração e ao governo eletrônico.

\section{Referências}

ABRAHAMSSON, Bengt. Bureaucracy or participation: the logic of organization. Beverly Hills: Sage, 1977.

AFONSO, Almerindo. Para uma conceptualização alternativa de accountability em educação. Educação e Sociedade, Campinas, v. 33, n. 119, p. 471-484, 2012.

ALBROW, Martin. Bureaucracy. Londres: Macmillan, 1970.

BACHARACH, Samuel B.; MUNDELL, Bryan L. Organizational politics in schools: micro, macro and logics of action. Educational Administration Quarterly, v. 29, n. 4, p. 423-452, 1993.

BALDRIDGE, J. Victor. Power and conflict in the university. New York: John Wiley; Sons, 1971.

BALL, Stephen J. Reformar escolas/reformar professores e os terrores da performatividade. Revista Portuguesa de Educação, Braga, v. 15, n. 2, p. 3-23, 2002.

BALL, Stephen J. Education PLC: understanding private sector participation in public sector education. Londres: Routledge, 2007. BIDWELL, Charles E. The school as a formal organization. In: MARCH, James G. (Ed.). Handbook of organizations. Chicago: Rand Mcnally, 1965. p. 972-1022.

BROADFOOT, Patricia. Educational assessment: the myth of measurement. In: WOODS, Peter (Ed.). Contemporary issues in teaching and learning. London: Routledge; The Open University, 1996. p. 203-230.

BURRELL, Gibson; MORGAN, Gareth. Sociological paradigms and organisational analysis. Guilford: Gower, 1979.

CLARKE, John; NEWMAN, Janet. The managerial state: power, politics and ideology in the remaking of social welfare. London: Sage, 1997.

CLEGG, Stewart R. Modern organizations: organization studies in the postmodern world. London: Sage, 1990.

COHEN, Michael D.; MARCH, James G. Leadership and ambiguity: the American college president. New York: McGraw-Hill, 1974.

COHEN, Michael D.; MARCH, James G.; OLSEN, Johan. P. A garbage can model of organizational choice. Administrative Science Quarterly, v. 17, n. 1, p. 1-25, 1972.

DIAS SOBRINHO, José. Avaliação da educação superior: avanços e riscos. EccoS, v. 10, n. esp., p. 67-93, 2008.

ETZIONI, Amitai. Análise comparativa das organizações complexas. São Paulo: Zahar, 1974.

FOUCAULT, Michel. Vigiar e punir: nascimento da prisão. Petrópolis: Vozes, 1998.

FREIRE, Paulo. Pedagogia da autonomia: saberes necessários à prática educativa. São Paulo: Paz e Terra, 1996.

HADJl, Charles. A avaliação, regras do jogo. Porto: Porto Editora, 1994.

ILLICH, Ivan. Sociedade sem escolas. Petrópolis: Vozes, 1977.

KELLER, Felix. Les "nomades" universitaires: géométrisation du savoir et art de naviguer. In: SCHULTHEIS, Franz; ROCA i ESCODA, Marta; COUSIN, Paul-Frantz (Dir.). Le cauchemar de Humboldt: les réformes de l'enseignement supérieur européen. Paris: Raisons D’Agir, 2008. p. 47-61.

LIMA, Licínio C. A escola como organização educativa: uma abordagem sociológica 3. ed. São Paulo: Cortez, 2008. 
LIMA, Licínio C. Concepções de escola: para uma hermenêutica organizacional. In: LIMA, Licínio C. (Org.). Compreender a escola: perspectivas de análise organizacional. Porto: Asa, 2006. p. 15-69.

LIMA, Licínio C. Elementos de análise organizacional das políticas e práticas de avaliação escolar. In: WERLE, Flávia 0. C. (Org.). Avaliação em larga escala: questões polêmicas. Brasília: Liber Livro, 2012b. p. 15-38.

LIMA, Licínio C. Elementos de hiperburocratização da administração educacional. In: LUCENA, Carlos; SILVA JÚNIOR, João dos Reis (Orgs.). Trabalho e educação no Século XXI: experiências internacionais. São Paulo: Xamã, 2012c. p. 129-158.

LIMA, Licínio C. 0 paradigma da educação contábil: políticas educativas e perspectivas gerencialistas no ensino superior em Portugal. Revista Brasileira de Educaçã̃o, São Paulo, n. 4, p. 43-59, 1997.

LIMA, Licínio C. Patterns of institutional management: democratization, autonomy and the managerialist canon. In: NEAVE, Guy; AMARAL, Alberto (Orgs.). Higher education in Portugal 1974-2009: a nation, a generation. Dordrecht: Springer, 2012a. p. 287-306.

LIMA, Licínio C. Universidade gestionária: hibridismo institucional e adaptação ao ambiente competitivo. In: CHAVES, Vera Jacob; SILVA JUNIOR João dos Reis; CATANI, Afrânio Mendes (Orgs.). A universidade brasileira e o PNE: instrumentalização e mercantilização educacionais. São Paulo: Xamã, 2013. p. 59-84.

MOUZELIS, Nicos P. Organisation and bureaucracy: an analysis of modern theories. Londres: Routlededge; Kegan Paul, 1975.

NEAVE, Guy. On the cultivation of quality, efficiency and enterprise: an overview of recent trends in higher education in Western Europe, 1986-1988. European Journal of Education, v. 23, n. 1/2, p. 7-23, 1988.

OLSEN, Johan P. Maybe it is time to rediscover bureaucracy. Journal of Public Administration Research and Theory, n. 16, p. 1-24, 2005. Disponível em: <http://resources.statsvet.uu.se/repository/1/extern/olsen.pdf>. Acesso em: 28 mai. 2014.

POLLITT, Christopher; BOUCKAERT, Geert. Public management reform. Oxford: Oxford University Press, 2011.

RAMIREZ, Francisco 0. World society and the university as formal organization, Sisyphus, Lisboa, v. 1, n. 1, p. 125-153, 2013.

ROSANVALLON, Pierre. La contre-démocratie: la politique à l'âge de la défiance. Paris: Éditions du Seuil, 2006.

SIMON, Herbert A. El comportamiento administrativo. Madrid: Aguilar, 1970.

SOROKIN, Pitirim A. Fads and foibles in modern sociology. Chicago: Gateway, 1965.

TORRES, Leonor Lima; PALHARES, José. Estilos de liderança e escola democrática. Revista Lusófona de Educação, Lisboa, n. 14, p. 77-99, 2009.

TRAGTENBERG, Maurício. Burocracia e ideologia. São Paulo: Unesp, 2006.

WEBER, Max. Economía y sociedad: esbozo de sociología comprensiva. México, DF.: Fondo de Cultura Económica, 1964.

WEICK, Karl E. Educational organizations as loosely coupled systems. Administrative Science Quarterly, v. 21, n. 1, p. 1-19, 1976.

YOUNG, Michael. The rise of the meritocracy 1870-2033: an essay on education and equality. London: Thames and Hudson, 1958.

Recebido em: 05.11.2014

Aprovado em: 24.03.2015

Licínio C. Lima é doutor em educação e agregado em sociologia da educação e administração educacional pela Universidade do Minho, onde é professor catedrático do Departamento de Ciências Sociais da Educação do Instituto de Educação e pesquisador do Centro de Investigação em Educação (CIEd). 